\title{
Managing sodium hypochlorite accidents: the reality of toxicity
}

SADJ July 2017, Vol 72 no 6 p271 - pxxx

E Patel', M Gangadin ${ }^{2}$

\section{ABSTRACT}

Sodium hypochlorite $(\mathrm{NaOCl})$ is the most commonly used endodontic irrigant due to its effective antimicrobial function and ability to dissolve organic matter. However, when $\mathrm{NaOCl}$ escapes from the root canal system, the cytotoxic effects are severe, regardless of the concentration used.

A case of undiagnosed external root resorption that lead to the extrusion of a $1 \% \mathrm{NaOCl}$ solution into the periapical soft tissues is presented. This report considers guidelines and highlights the obligation of clinical practices to develop protocols for, and to maintain, the ability to manage and treat accidents involving $\mathrm{NaOCl}$.

Keywords: Sodium hypochlorite accident, irrigation toxicity, tissue necrosis.

\section{INTRODUCTION}

The earliest reported use of sodium hypochlorite ( $\mathrm{NaOCl}$ ) was limited to stain removal in clothing. The first evidence of its use in endodontics was published by Coolidge and Crane in 1919 and 1920, respectively, long after it had been recognized in 1843 as an antimicrobial agent. $\mathrm{NaOCl}$ continues today to serve as an endodontic irrigant, its popularity stemming from its role in the dissolution of organic matter., ${ }^{1,2}$ The hypochlorite ion irreversibly oxidizes enzymes, thereby terminating the metabolic activities of tissues or organisms it contacts. The reaction of $\mathrm{NaOCl}$ with lipids and amino acids in pulpal tissue leads to liquefactive necrosis within minutes. ${ }^{3-7}$

There is no consensus as to the most effective concentration of $\mathrm{NaOCl}$ when used as endodontic irrigant, but an empirical concentration range of $0.5 \%$ to $\geq 5.25 \%$ is generally accepted. . $^{8-10}$

1. Ebrahim Patel: BDS, MScDent. Lecturer, Division of Operative Dentistry and Endodontics, Department of Oral Rehabilitation, School of Oral Health Science, Faculty of Health Sciences, University of the Witwatersrand.

2. Megna Gangadin: BDT, BDS, PG Dip Dent. Lecturer, Division of Operative Dentistry and Endodontics, Department of Oral Rehabilitation, School of Oral Health Science, Faculty of Health Sciences, University of the Witwatersrand.

\section{Corresponding author}

\section{Ebrahim Patel:}

Department of Oral Rehabilitation, School of Oral Health Sciences, Faculty of Health Sciences, University of the Witwatersrand, South Africa, 7 York Road, Parktown, 2193. Cell: 0824955164.

E-mail: ebrahim.patel@wits.ac.za

\section{ACRONYMS}

NaOCl: sodium hypochlorite

NSAID: non-steroidal anti inflammatory drug

An increase in $\mathrm{NaOCl}$ concentration leads to an increase in cytotoxicity. ${ }^{11}$

We present a protocol for the management of a $\mathrm{NaOCl}$ accident with an illustrative case.

\section{CASE REPORT}

A 70 year old female patient with a complex medical history presented to the Wits Oral Health Centre with a main complaint of 'feeling an abscess in her front tooth'. Highlights from her medical history included hypertension, hyperlipidaemia, a peptic ulcer, an earlier angiogram and cardiac coronary bypass, a cataract in right eye, and a hypersensitivity to penicillin. She explained that for one week she had noticed pus draining from the gum area below her lower front tooth. She had no associated pain. Her dental history included multiple prior extractions due to caries and she wore a single maxillary complete denture constructed in 2001.

Extra-oral examination revealed bilateral masseteric tenderness. Intra-orally, only the six lower anterior teeth were present, all with generalized attrition. The right lower lateral incisor was tender to percussion and nonresponsive to thermal tests. A buccal vestibular draining sinus with inflammation of the adjacent labial mucosa was found. Radiographically, widening of the lamina dura in the apical third of the tooth was observed. Root canal treatment was initiated for the lower right lateral incisor. The endodontic protocol of the clinic was followed and included rubber dam isolation, access cavity preparation using the Endo Access Kit ${ }^{\circledR}$ (Dentsply, South Africa), and extirpation using k-files. Irrigation was performed using a $1 \% \mathrm{NaOCl}$ solution via a side-ported needle and syringe delivery. $\mathrm{NaOCl}$ was introduced into the coronal third of the root canal and thereafter advanced to the middle third. The patient reported severe burning with pain radiating down the neck following syringe withdrawal. As per protocol (Table 1) aspiration of the residual $\mathrm{NaOCl}$ was immediately attempted. Local anaesthetic (Xylotox E80-A) and saline were introduced to dilute the effects of the $\mathrm{NaOCl}$ as well as to assist with analgesia. A calcium hydroxide dressing (AH Temp ${ }^{\circledR}$; Dentsply, South Africa) was inserted into the root canal after which a resin- 
Table 1: Clinical Guidelines following NaOCl accident of the Wits Oral Health Centre (Adapted from Bosch-Aranda et al. 2012)

$\begin{array}{ll}\text { Period } & \text { Action } \\ \text { Immediately } & \text { 1. Aspiration of all possible NaOCl from site of entry } \\ \text { following } & \text { 2. Local anaesthetic to assist analgesia } \\ \text { extrusion of/ } & \text { 3. Saline to assist dilution of the irrigant } \\ \text { exposure to } & \text { 4. Tooth temporized with a calcium hydroxide intra-canal medicament and resin-modified glass ionomer restoration } \\ \mathrm{NaOCl} & \text { 5. Prescribe analgesics and anti-inflammatories (First choice is NSAIDS such as Ibuprofen. If contraindicated then } \\ & \begin{array}{l}\text { 6. } \text { a steroid such as methylprednisolone and an opioid such as tramadol, where indicated) } \\ \text { 7. Patient must be advised to apply cold packs to facial region (to prevent/limit further swelling) }\end{array} \\ \begin{array}{ll}\text { 74 hours } & \text { 1. Assess clinical sequelae of accident and severity } \\ \text { post-accident } & \text { 2. Antibiotics - prescribed on basis of anticipated necrosis } \\ & \text { 3. Chlorhexidine mouthwash } \\ 7 \text { days } & \text { 4. Patient must be advised to apply hot packs and rinse frequently with warm oral rinses (to stimulate local circulation) } \\ \text { post-accident } & \text { 1. Reassess clinical sequelae and severity } \\ 14 \text { days } & \text { 2. Maxillofacial consultation } \\ \text { post-accident } & \text { 1. Reassess healing to date } \\ & \text { 2. Continue with endodontic treatment (if healing satisfactory) } \\ & \text { 3. Alternate irrigants must be used (eg. EDTA, Chlorhexidine) }\end{array}\end{array}$

modified glass ionomer (Vitremer ${ }^{\circledR}$; 3M, South Africa) was placed as a temporary restoration. An analgesic (Tramadol, 50mg, twice daily) and a steroid (Methlyprednisolone, $20 \mathrm{mg}$, at night for five days) were prescribed. Antibiotics were not prescribed at this stage as major necrosis was not envisaged.

The patient was contacted telephonically in the first 24 hours and was clinically reassessed at 48 hours postaccident. Several signs and symptoms were observed including: pain, dysphagia, and a midline swelling in the neck extending down to the level of the hyoid bone which was tender to palpation (Figure $2 \mathrm{~A}, \mathrm{~B}$ ). Intra-orally, buccal gingival necrosis was noted about $1 \mathrm{~cm}$ in diameter and with a mildly erythematous border (Figure 3 A). Superficial sublingual necrosis, approximately $2 \mathrm{cms}$ in diameter, was also observed in the mucosa of the floor of the mouth (Figure 3B). At this stage, an antibiotic (Clindamycin, 300mg, twice daily for five days), coupled with a chlorhexidine mouthwash was prescribed. Clindamycin was chosen for this patient due to her penicillin hypersensitivity; and the twice daily regimen provides for better patient compliance than a 6-hourly dose.

The patient was recalled again eight days after the incident. She reported that whilst the pain had dissipated, her dysphagia had still persisted. Extra-orally, resolution of the neck swelling could be appreciated (Figure 2C, D). Intraorally, the buccal gingiva healed uneventfully (Figure 4A). The previously superficial sublingual necrosis advanced to an ulcer with the concomitant development of a second ulcer in the contralateral side of the floor of the mouth (Figure 4B). At this stage class III mobility was recorded for the lower right lateral incisor and canine. As outlined by the protocol in Table 1, these findings prompted consultation with a maxillofacial surgeon who further guided the management of this case, and the patient was assessed bi-weekly.

At eight weeks post-accident, the patient was re-examined and the panoramic radiograph displayed a radiolucent lesion, extending $20 \mathrm{~mm}$ apical to the lower right lateral incisor, approximately $15 \mathrm{~mm}$ in width (Figure 5). This finding, coupled with the persistent class III mobility on the lower right lateral incisor and canine led to both teeth being extracted. Four months later complete healing had taken place. The treatment plan was resumed and a mandibular partial denture was constructed.

\section{DISCUSSION}

Sodium hypochlorite is the most commonly used endodontic irrigant worldwide and continues to be favoured as it remains the only material capable of dissolving organic tissue within the root canal system. ${ }^{10,12-17}$ Although $\mathrm{NaOCl}$ is regarded as safe for endodontic use, the cytotoxic results of mishaps and/or accidents must be highlighted. It is essential that clinicians are trained, and remain skilled and equipped, to deal immediately and effectively with any repercussions of a $\mathrm{NaOCl}$ accident.

The concentration of $\mathrm{NaOCl}$ required to efficiently disinfect the root canal system has long been a topic of debate. The Wits Oral Health Centre (Johannesburg, South Africa) employs a $1 \% \mathrm{NaOCl}$ solution in its undergraduate endodontic clinic. The rational for this is that: (a) comparatively lower concentrations are safer

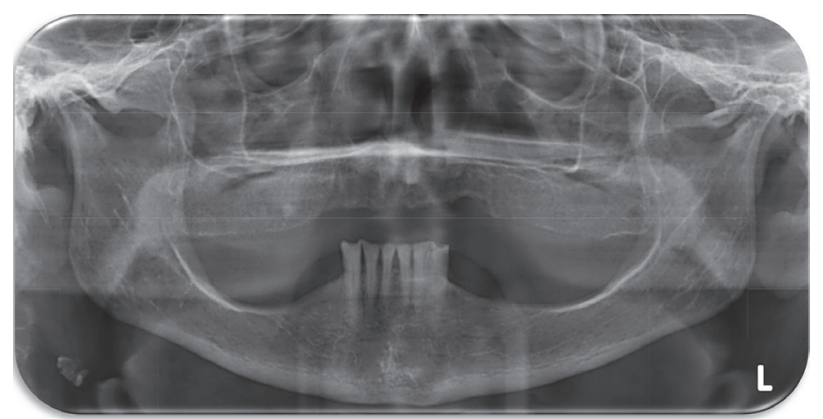

Figure 1: Preoperative panoramic radiograph exhibiting the six remaining mandibular teeth

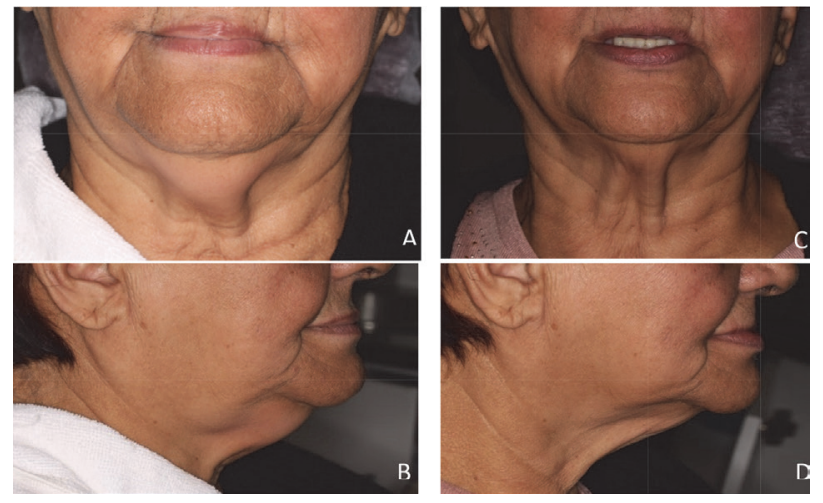

Figure 2: Comparative decrease in the neck swelling from 48 hours postaccident $(A, B)$ to that of eight days after $(C, D)$. 
for use by novice clinicians, and (b) by increasing the volume of irrigant used, with regular exchange, the antimicrobial efficacy of lower concentrations of $\mathrm{NaOCl}$ solution is sustained. ${ }^{18}$ This case reinforces the fact that even at reduced concentrations, $\mathrm{NaOCl}$ retains potent cytotoxicity that demands extreme caution during use.

$\mathrm{NaOCl}$ extrusion beyond the apical foramen is an infrequent occurrence and is rarely reported. However, iatrogenic damage and/or pathologic processes such as root canal perforation, poor length control during canal preparation, and external root resorption favour this complication when their presence is undiagnosed. ${ }^{27}$ In this case, external root resorption in the apical third of the root canal, undetectable with routine two dimensional apical radiographs, permitted the exit of the $\mathrm{NaOCl}$ into the periapical tissue. The incident highlights the limitations of two-dimensional radiographs in endodontic diagnosis and preoperative assessment.
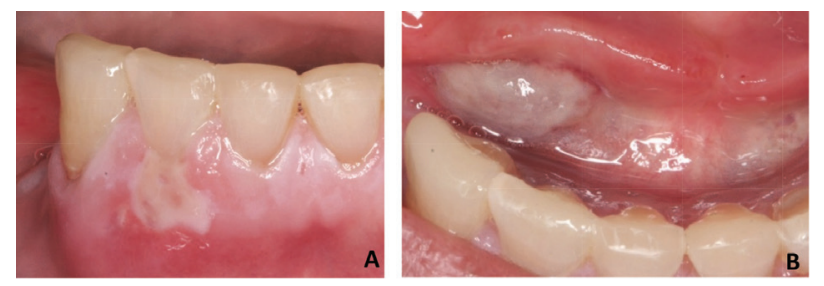

Figure 3: .A: Irregular buccal gingival necrosis (lower right lateral incisor) approximately $1 \mathrm{~cm}$ in diameter. B: Sublingual superficial necrosis posterior to the lower right lateral incisor, with an erythematous border.
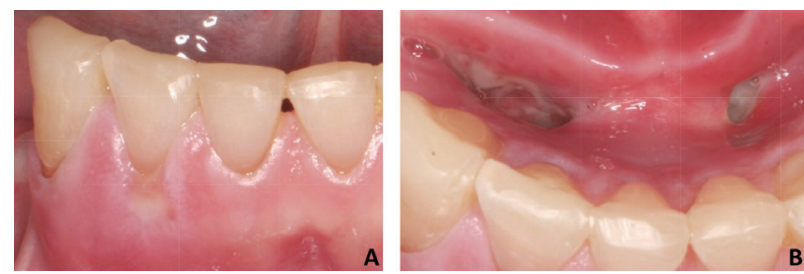

Figure 4: A: Buccal gingival healing observed eight days post-accident. $\mathrm{B}$ : Advancement of the sublingual necrosis to complete ulceration with the addition of a secondary ulcer in the sublingual region adjacent to the lower left lateral incisor.

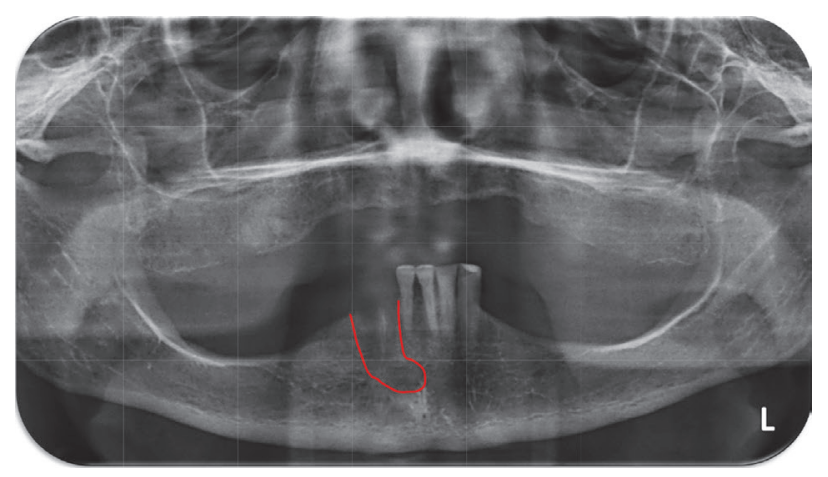

Figure 5: Panoramic radiograph following extraction of the lower right lateral incisor and canine. The red marking delineates the extent of the radiolucent area observed beyond the extracted teeth.

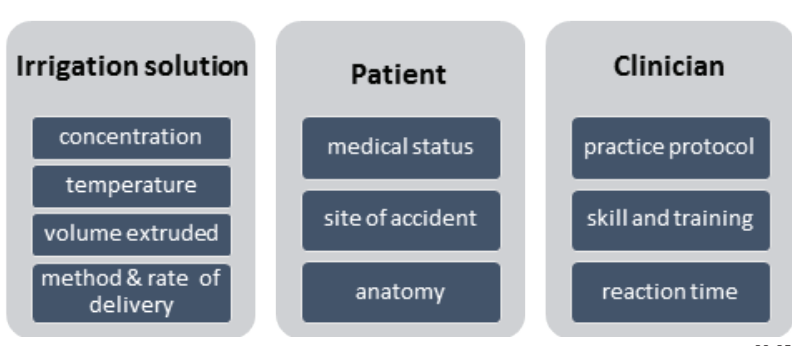

Figure 6: Factors contributing to the clinical severity of $\mathrm{NaOCl}$ accidents. ${ }^{30-35}$
The commonly reported clinical sequelae following a $\mathrm{NaOCl}$ accident include: pain, ecchymosis, swelling, chemical burns and necrosis, ulceration, neurologic damage (paraesthesia and anaesthesia) and at times respiratory compromise. Multiple factors influence the progression of these clinical sequelae (Figure 6). The volume of $\mathrm{NaOCl}$ that enters the tissues and the clinician's reaction time to recognize and initiate treatment protocols have perhaps the most critical influence..$^{19-25}$

Pain is a hallmark of tissue injury and was reported in this case within seconds of the accident. Swelling of the surrounding mucosa, subcutaneous tissue and skin occurred a few hours later. This inflammatory response originates from the reaction of hypochlorite ions with proteins and lipids resulting in soluble soap complexes that facilitate the permeation of the ion deeper into the tissue. This process complicates efforts to neutralize or dilute the $\mathrm{NaOCl}^{3,26}$ Furthermore, tissue necrosis of the fascial spaces is not uncommon in cases of $\mathrm{NaOCl}$ extrusion and is a direct result of a chemical burn in the tissue.

In a review of clinical characteristics following $\mathrm{NaOCl}$ accidents, Zhu et al. (2013) observed reports of a higher occurrence of ecchymosis in the periorbital and angle of mouth regions. ${ }^{27}$ According to their findings, the mode of spread was associated with anastomoses around the facial vein that permitted the rapid spread of the $\mathrm{NaOCl}$ solution. Minimal bruising/ecchymosis was observed in this case due to the anatomy of the sublingual fascial space.

Anatomically, the sublingual space is delineated by the mucosa of the floor of the mouth superiorly, the mylohyoid muscle inferiorly and the lingual surface of the mandible laterally. Its contents include the submandibular (Whartons) duct, lingual nerve, sublingual gland and the sublingual artery and vein. ${ }^{28}$ The space is divided in the midline only by loose connective tissue which explains the spread of the $\mathrm{NaOCl}$ to the contralateral side (from the sublingual region of tooth 42 to that of tooth 32). Furthermore, the mucosa of the floor of the mouth is classified histologically as lining mucosa - a thin, non-keratinized layer of epithelium with an underlying lamina propria. ${ }^{29}$ The friable nature of this tissue and its relative inability to act as an effective barrier against $\mathrm{NaOCl}$ further explains the chemical burns and subsequent ulcers that were encountered in both the right and left sublingual regions.

Antibiotics, analgesics and anti-inflammatory drugs are often prescribed following a $\mathrm{NaOCl}$ accident. The choice of drugs used for this case was selected based on the patient's medical conditions. Although a non-steroidal anti-inflammatory (NSAID) is the first drug of choice to limit immediate swelling, a steroid (methylprednisolone) was prescribed in this case due to the patient's intolerance to NSAIDS. In addition, the gastrointestinal side effects of the steroid were neutralized by the patient's chronic medication - Omeprazole (20mg). Even though antibiotic prescription is based on the merit of each $\mathrm{NaOCl}$ accident case, and on the expectancy of moderate to severe necrosis of the affected tissue, it is still largely empirical.

In this case, the decision to delay prescribing an antibiotic was due to the clinician envisaging minimal to no tissue necrosis. However, following observation of the resultant buccal and lingual necrosis at the 48 hour recall visit this decision was revised to prevent the development of secondary infection. Clindamycin is the second drug of choice where patients are allergic to penicillin and was 
prescribed as the preferred twice-daily dose to improve compliance over the 6-hourly dose.

Exigency is an important factor for the successful management of $\mathrm{NaOCl}$ accidents. The time taken by clinicians to recognize and diagnose the incident, and the immediate implementation of a $\mathrm{NaOCl}$ incident protocol have an influence on the severity and outcome of the clinical sequelae in the days that follow. The Wits Oral Health Centre follows a specific set of guidelines developed for the management of $\mathrm{NaOCl}$ accidents (Table 1). These guidelines emphasise the uniqueness of each case and that intervention or treatment decisions are made on a case-to-case basis that relies on additional empirical input. The follow-up period varies based on the specific signs and symptoms that present in each patient during the course of the incident. In this case, the patient was recalled (in addition to the guidelines) at four weeks, six weeks and eight weeks post-accident. This was due to the persistent mobility on teeth 42 and 43 , which were extracted at week eight. Healing of the extraction sites was uneventful.

\section{CONCLUSION}

$\mathrm{NaOCl}$ remains the irrigant of choice for endodontic treatment due to its ability to dissolve organic tissue and resultant antimicrobial activity. However, the cytotoxicity of the medication requires caution during clinical procedures. Not only is it imperative that undergraduate and postgraduate endodontic curriculums highlight the possibility of $\mathrm{NaOCl}$ accidents, the avoidance and the management thereof, but that clinicians remain skilled and equipped to deal appropriately and timeously with the repercussions of an accident.

Conflict of Interest: None declared

\section{References}

1. Coolidge ED. The diagnosis and treatment of conditions resulting from diseased dental pulps. The Journal of the National Dental Association 1919; 6: 337-49.

2. Crane AB. A Predictable Root Canal Technique. Philadelphia: Lea \& Febiger. 1920:69.

3. Estrela C, Estrela CRA, Barbin EL, Spanó JCE, Marchesan MA, Pécora JD. Mechanism of action of sodium hypochlorite. Brazilian Dental Journal 2002; 13: 113-7.

4. Fukuzaki S. Mechanisms of actions of sodium hypochlorite in cleaning and disinfection processes. Biocontrol Science 2006; 11: 147-57.

5. Hand RE, Smith ML, Harrison JW. Analysis of the effect of dilution on the necrotic tissue dissolution property of sodium hypochlorite. Journal of Endodontics 1978; 4: 60-4.

6. Baumgartner JC, Cuenin PR. Efficacy of several concentrations of sodium hypochlorite for root canal irrigation. Journal of Endodontics 1992; 18: 605-12.

7. Stojicic S, Zivkovic S, Qian W, Zhang H, Haapasalo M. Tissue dissolution by sodium hypochlorite: effect of concentration, temperature, agitation, and surfactant. Journal of Endodontics. 2010;36(9):1558-62.

8. Gomes B, Ferraz CCR, Vianna ME, Berber VB, Teixeira FB, Souza-Filho FJ. In vitro antimicrobial activity of several concentrations of sodium hypochlorite and chlorhexidine gluconate in the elimination of Enterococcus faecalis. International Endodontic Journal 2001; 34: 424-8.

9. Berber VB, Gomes BPFA, Sena NT, Vianna ME, Ferraz CCR, Zaia AA, Souza-Filho FJ. Efficacy of various concentrations of $\mathrm{NaOCl}$ and instrumentation techniques in reducing Enterococcus faecalis within root canals and dentinal tubules. International Endodontic Journal 2006; 39: 10-7.

10. Haapasalo M, Shen Y, Wang Z, Gao Y. Irrigation in Endodontics. British Dental Journal 2014; 216: 299-303.

11. Alkahtani A, Alkahtany SM, Anil S. An in vitro evaluation of the cytotoxicity of varying concentrations of sodium hypochlorite on human mesenchymal stem cells. Journal of Contemporary Dental Practice 2014; 15: 473-81.
12. Dutner J, Mines $P$, Anderson A. Irrigation trends among American Association of Endodontists Members: A webbased survey. Journal of Endodontics 2012; 38: 37-40.

13. Unal GC, Kaya BU, Tac AG, Kececi AD. Survey of attitudes, materials and methods preferred in root canal therapy by general dental practice in Turkey: Part 1. European Journal of Dentistry 2012; 6: 376-84.

14. Udoye Cl, Sede MA, Jafarzadeh $\mathrm{H}$, Abbott PV. A survey of endodontic practices among dentists in Nigeria. The Journal of Contemporary Dental Practice 2013; 14: 293.

15. Willershausen I, Wolf TG, Schmidtmann I, Berger C, Ehlers V, Willershausen B, Briseño B. Survey of root canal irrigating solutions used in dental practices within Germany. International Endodontic Journal 2015; 48: 654-60.

16. Tosic G, Miladinovic M, Kovacevic M, Stojanovic M. Choice of root canal irrigants by Serbian dental practitioners. Vojnosanitetski Pregled 2016; 73: 47-52.

17. Cobankara FK, Ozkan HB, Terlemez A. Comparison of organic tissue dissolution capacities of sodium hypochlorite and chlorine dioxide. Journal of Endodontics 2010; 36: 272-4.

18. Siqueira JF, Rôças IN, Favieri A, Lima KC. Chemo-mechanical reduction of the bacterial population in the root canal after instrumentation and irrigation with $1 \%, 2.5 \%$, and $5.25 \%$ sodium hypochlorite. Journal of Endodontics 2000; 26: 331-4.

19. Bosch-Aranda M, Canalda-Sahli C, Figueiredo R, GayEscoda C. Complications following an accidental sodium hypochlorite extrusion: A report of two cases. Journal of Clinical and Experimental Dentistry 2012; e194-e198.

20. Aguiar BA, Gomes FA, Ferreira CM, Sousa BCD, Costa FWG. Hypochlorite-induced severe cellulitis during endodontic treatment: case report. RSBO (Online) 2014; 11(2): 199-203.

21. Gomes FA, Costa FW, Sousa BC, Aguiar BA, Ferreira $\mathrm{CM}$. Hypochlorite-induced severe cellulitis during endodontic treatment: case report. Revista Sul-Brasileira de Odontologia 2014; 11: 199-203.

22. Goswami M, Chhabra N, Kumar G, Verma M, Chhabra A. Sodium hypochlorite dental accidents. Paediatrics and International Child Health 2014; 34: 66-9.

23. Matthews J, Merrill RL. Sodium hypochlorite-related injury with chronic pain sequelae. The Journal of the American Dental Association 2014; 145: 553-5.

24. Al-Sebaei M, Halabi O, El-Hakim I. Sodium hypochlorite accident resulting in life-threatening airway obstruction during root canal treatment: a case report. Clinical, Cosmetic and Investigational Dentistry 2015; 41: doi:10.2147/CCIDE.S79436.

25. Chaugule VB, Panse AM, Gawali PN. Adverse reaction of sodium hypochlorite during endodontic treatment of primary teeth. International Journal of Clinical Paediatric Dentistry 2015; 8: 153-6.

26. Thé SD, Maltha JC, Plasschaert AJ. Reactions of guinea pig subcutaneous connective tissue following exposure to sodium hypochlorite. Oral Surgery Oral Medicine Oral Pathology 1980; 49: 460-6.

27. Zhu W, Gyamfi J, Niu L, Schoeffel GJ, Liu S, Santarcangelo F, Khan S, Tay KC-Y, Pashley DH, Tay FR. Anatomy of sodium hypochlorite accidents involving facial ecchymosis-A review. Journal of Dentistry 2013; 41: 935-48.

28. Andersson L, Kahnberg K-E, Pogrel MA. Oral and Maxillofacial Surgery. John Wiley \& Sons, 2012: pp. 510.

29. Chiego Jr DJ. Essentials of Oral Histology and Embryology Elsevier on Vital Source: A Clinical Approach. Elsevier Health Sciences, 2014: pp. 169.

30. Hülsmann M, Hahn W. Complications during root canal irrigation-literature review and case reports. International Endodontic Journal 2000; 33: 186-93.

31. Gernhardt CR, Eppendorf K, Kozlowski A, Brandt M. Toxicity of sodium hypochlorite used as an endodontic irrigant. International Endodontic Journal 2004; 37: 272-80.

32. Spencer HR, Ike V, Brennan PA. Review: the use of sodium hypochlorite in endodontics - potential complications and their management. British Dental Journal 2007; 202: 555-9.

33. Kleier DJ, Averbach RE, Mehdipour O. The sodium hypochlorite accident: experience of diplomates of the American Board of Endodontics. Journal of Endodontics 2008; 34: 1346-50.

34. Mohammadi Z. Sodium hypochlorite in endodontics: an update review. International Dental Journal 2008; 58: 329-41.

35. Farook SA, Shah V, Lenouvel D, Sheikh O, Sadia Z, Cascarini L. Guidelines for management of sodium hypochlorite extrusion injuries. Brazilian Dental Journal 2014; 217: 679-84. 